\title{
Structural Studies of Sm/Zr Substituted Mg-Mn Ferrites
}

\author{
G.BHANU PRAVEEN* ${ }^{*}$ and A. D. P.RAO \\ Department of Nuclear Physics, Andhra University, Visakhapatnam 530003, India \\ gbhanupraveen@gmail.com
}

Received 4 September 2018 / Accepted 3 October 2018

\begin{abstract}
Two series of $\mathrm{Sm} / \mathrm{Zr}$ substituted Mg-Mn ferrite materials have been developed having the chemical compositions $\mathrm{Mg}_{0.95} \mathrm{Mn}_{0.05} \mathrm{Sm}_{2 \mathrm{x}} \mathrm{Fe}_{2-2 \mathrm{x}} \mathrm{O}_{4}$ and $\mathrm{Mg}_{0.95} \mathrm{Mn}_{0.05+\mathrm{x}} \mathrm{Zr}_{\mathrm{x}} \mathrm{Fe}_{2-2 \mathrm{x}} \mathrm{O}_{4}$. These materials nanoparticles size ferrites are prepared by using sol-gel method while following ceramic method bulk (larger particle size) ferries are prepared. The value of $\mathrm{x}$ varies from 0.0 to 0.5 . These are characterized with density, XRD, EDAX, SEM and TEM studies. Based on the obtained results cation distribution is proposed. Samarium is found to occupy B sites while zirconium occupied A and $\mathrm{B}$ sites replacing $\mathrm{Fe}^{3+}$ ions. Density of all the materials found to increase except at higher values of Sm concentration. Lattice parameter of Sm substituted ferrites is found to increase with the rise of $\mathrm{Sm}$ content while it decreases with the rise of $\mathrm{Zr}$ content. These values obtained due to XRD studies have fair agreement with the theoretically computed lattice parameter values based on the proposed cation distribution. Obtained particle size values due to XRD, SEM and TEM are compared, which are in the nano range.
\end{abstract}

Keywords: Lattice parameter, Particle size, Cation distribution, Bond length, Structure

\section{Introduction}

Investigations related to nanoparticle size ferrite materials have shown difference in behavior of their physical properties relative to those materials bulk particle size ferrites physical properties behavior ${ }^{1-3}$. It indicates that understanding of science related to a particular material in nano scale is different from its bulk size. Therefore investigations simultaneously on bulk as well as nano scale ferrite materials are essential to understand difference between sciences of these two sizes of materials.

Presently, there is a great interest in the materials that exhibit interplay between lattice distortions and electrical as well as magnetic ordering of novel compounds; which display both ferroelectricity and ferromagnetic behavior known as multiferroic ${ }^{4-7}$ materials. These are useful to design sensors, transformers, multi-memory state devices etc. Multiferroic materials show phenomena of electrical polarization by an application of external electric field besides their ferromagnetic nature, providing an additional degree of freedom for the design of new devices. Therefore, development of such kind of materials in which magnetic and electric order coexist would be a milestone in the modern era of technology. 
Investigations on multiferroic materials are limited ${ }^{7}$ thus studies are needed to understand physics of these materials. These show exhibit anti-ferromagnetic nature at low temperature and ferroelectric at high temperature. Earlier investigators reported about multiferroic nature of Mg-Mn ferrite materials ${ }^{8}$. They are dominantly used in multilayer ferrites chip inductor (MLFCI), with better high frequency properties and low densification temperature ${ }^{9}$. Hence, $\mathrm{Mg}-\mathrm{Mn}$ ferrites are commercially important because of their excellent magnetic and electrical properties ${ }^{9}$. The aim of the present work is to develop multiferroic $\mathrm{Mg}-\mathrm{Mn}$ ferrite new materials (both nano particle size and bulk size) by substitution of trivalent and/or tetravalent valence cations $v i z$. $\mathrm{Sm} / \mathrm{Zr}$ and study their physical properties.

\section{Samples preparation}

Two series of $\mathrm{Mg}-\mathrm{Mn}$ ferrites were prepared having the chemical composition $\mathrm{Mg}_{0.95} \mathrm{Mn}_{0.05} \mathrm{Sm}_{2 \mathrm{x}} \mathrm{Fe}_{2-2 \mathrm{x}} \mathrm{O}_{4}$ as $1^{\text {st }}$ series and $\mathrm{Mg}_{0.95} \mathrm{Mn}_{0.05+\mathrm{x}} \mathrm{Zr}_{\mathrm{x}} \mathrm{Fe}_{2-2 \mathrm{x}} \mathrm{O}_{4}$ is $2^{\text {nd }}$ series ( $\mathrm{x}=0.0$ to 0.5 in steps of 0.1 ). These were prepared by the standard conventional ceramic method to obtain bulk particle size materials ${ }^{10-14}$. Nanoparticle size ferrites were synthesized by following citrate sol-gel auto combustion method ${ }^{15-17}$. The starting materials are highly pure analytical reagent grade $(99.9 \%)$. The present materials were calcinated in air for 4 hours at $950{ }^{\circ} \mathrm{C}$; Pre-sintered powder mixed with $5 \%$ weight polyvinyl alcohol (PVA) as a binder; pressed into pellets at a pressure of 2.5 tone per square $\mathrm{cm}$. These pellets were sintered for 2 hours at $1200{ }^{\circ} \mathrm{C}$ and later switched off the furnace for cooling naturally ${ }^{11}$.

For nano size ferrite materials preparation, the starting materials are magnesium nitrate, manganese nitrate, ferric-nitrate, samarium nitrate, zirconyl nitrate, ammoniasolution and citric acid. In citrate sol-gel auto combustion method ${ }^{18}$, citric acid to the total moles of nitrate ions is adjusted to the ratio 1:3. The mixture was stirred for 30 minutes with 300 RPM to get a homogenous solution for pre mixing of each sample; later slowly heated to 80 ${ }^{\circ} \mathrm{C}$ at a rate of $5{ }^{\circ} \mathrm{C}$ per min by using a hot plate magnetic stirrer for 3 hours; $\mathrm{pH}$ of the solution is adjusted to 7 by adding ammonia solution; thus a sol is formed. The resulting solutions were evaporated to dryness by heating at $80{ }^{\circ} \mathrm{C}$ on a hot plate with continuous stirring about 24 hours and form a viscous gel. All water molecules were removed from gel by increasing temperature slowly; the gel gave a flameless auto combustion reaction by emitting large amount of gases at $200{ }^{\circ} \mathrm{C}$. Finally obtained dark grey voluminous was grounded and powdered ${ }^{15-17}$. The powdered sample was calcinated and then sintered as performed for bulk particle size ferrite materials.

\section{Experimental}

By using Archimedes principle; bulk density and apparent porosity of sintered pellets were determined $^{12}$. Dry weight along with soaked weight of sintered pellets and suspended weight of the samples in a beaker that contain water were recorded through an electronic balance. Then the beaker was kept in chamber to make it vacuum so as to ensure all the open pores were filled up with water. Ferrite porosity relative to the volume of its pores was derived by doing comparison of the bulk density $\left(d_{b}\right)$ with the $x$-ray density $\left(d_{x}\right)$ of samples. The difference of these two density values gives the $\%$ of porosity, which influences the physical properties of ferrites. Based on the obtained results of density; pore fraction percentage also evaluated ${ }^{19}$.

At room temperature XRD pattern were obtained for both bulk and nano size materials in the range of Bragg angle $20^{\circ}$ to $80^{\circ}$. These patterns indicate formation of single phase cubic spinel structure. The technical features of XRD include Lynxeye detector ${ }^{20}$ consisting of $\mathrm{Cu}$ tube with $1.5418 \AA$ A wave length, $40 \mathrm{kV}$ voltage, $40 \mathrm{~mA}$ current, $1600 \mathrm{~W}$ power, advanced D8 
controller that coupled $2 \theta / \theta, 2 \theta$ with increment of 0.020260 having primary slit width $0.600 \mathrm{~mm}$ and secondary slit width $6.000 \mathrm{~mm}$. This facility was utilized at IITB, Bhubaneswar.

Surface analyses of materials were performed by using scanning electron microscope (SEM) that equipped with an energy dispersive spectrometer (EDS) and transmission electron microscope (TEM). The former instrument was manufactured by JES Company, model JES-FA 100 ESR spectrometer ${ }^{21}$. This equipment was utilized at advanced analytical laboratory, Andhra University, Visakhapatnam. The later (TEM) was manufactured by the PHILIPS Company; model CM $200^{22}$ having operating voltages $20-200 \mathrm{kV}$ with the resolution $2.4 \AA$. TEM images are formed on using transmitted electrons instead of the visible light that can produce magnification up to $1,000,000 \mathrm{x}$ with a resolution better than $10 \AA$. This technique is utilized at IIT, Mumbai (temlab@iitb.ac.in).

\section{Results and Discussion}

The evaluated density values are presented in the Tables 1 and 2 for samarium substituted and zirconium substituted ferrites for bulk particle sizes respectively. The value of density found to show its increase as a function of substituent concentration ( $x$ ) for both the elements except at higher concentration of $(\mathrm{x})$ samarium substitution. This may be due to enhanced compactness of particles in their binding resulting to raise density of materials strength. The obtained theoretical density $\left(\mathrm{d}_{\mathrm{x}}\right)$ values of $\mathrm{Sm}$ substituted ferrites are found to show higher relative to measured values $\left(d_{b}\right)$ while converse is observed in the case of $\mathrm{Zr}$ substituted materials. This can be understood with the increased molecular weight of the samples due to their composition causing to increase the Sm content. The porosity of $\mathrm{Zr}$ materials found to be lower relative to $\mathrm{Sm}$ ferrites.

Table 1. Variation of bulk $\left(\mathrm{d}_{\mathrm{b}}\right)$ and $\mathrm{x}$-ray $\left(\mathrm{d}_{\mathrm{x}}\right)$ densities $(\mathrm{g}$ per $\mathrm{cm})$ besides porosity $\%$ with substituent concentration ( $\mathrm{x}$ ) for bulk size ferrites

\begin{tabular}{ccccccc}
\hline Conc & \multicolumn{3}{c}{ Sm substituted } & \multicolumn{3}{c}{ Zr substituted } \\
\hline$(\mathrm{x})$ & $\mathrm{d}_{\mathrm{b}}$ & $\mathrm{d}_{\mathrm{x}}$ & \% of porosity & $\mathrm{d}_{\mathrm{b}}$ & $\mathrm{d}_{\mathrm{x}}$ & \% of porosity \\
\hline 0.0 & 4.04 & 3.97 & 1.67 & 4.04 & 3.97 & 1.67 \\
0.1 & 4.26 & 4.27 & 0.16 & 4.22 & 4.11 & 2.63 \\
0.2 & 4.27 & 4.48 & 4.73 & 4.38 & 4.21 & 3.83 \\
0.3 & 4.36 & 4.67 & 6.74 & 4.47 & 4.32 & 3.40 \\
0.4 & 4.00 & 4.84 & 17.31 & 4.52 & 4.45 & 1.65 \\
0.5 & 4.19 & 4.90 & 14.37 & 4.69 & 4.53 & 3.68 \\
\hline
\end{tabular}

Table 2. Variation of bulk $\left(\mathrm{d}_{\mathrm{b}}\right)$ and $\mathrm{x}$-ray $\left(\mathrm{d}_{\mathrm{x}}\right)$ densities $(\mathrm{g}$ per $\mathrm{cm})$ besides porosity $\%$ with substituent concentration $(\mathrm{x})$ for nano size ferrites

\begin{tabular}{ccccccc}
\hline Conc. & \multicolumn{3}{c}{ Sm substituted } & \multicolumn{3}{c}{ Zr substituted } \\
\hline (x) & $\mathrm{d}_{\mathrm{b}}$ & $\mathrm{d}_{\mathrm{x}}$ & \% of porosity & $\mathrm{d}_{\mathrm{b}}$ & $\mathrm{d}_{\mathrm{x}}$ & \% of porosity \\
\hline 0.0 & 4.10 & 4.04 & 1.47 & 4.10 & 4.04 & 1.47 \\
0.1 & 4.17 & 4.35 & 4.11 & 4.24 & 4.11 & 3.18 \\
0.2 & 4.28 & 4.60 & 6.71 & 4.27 & 4.24 & 2.31 \\
0.3 & 4.39 & 4.84 & 9.31 & 4.30 & 4.37 & 1.44 \\
0.4 & 4.27 & 5.09 & 15.96 & 4.44 & 4.46 & 1.05 \\
0.5 & 4.14 & 5.35 & 22.60 & 4.57 & 4.54 & 0.65 \\
\hline
\end{tabular}

The XRD spectra related to $\mathrm{Sm} / \mathrm{Zr}$ substituents for bulk size ferrite materials are shown in the Figure 1 and Figure 2 respectively. At room temperature; the obtained XRD patterns 
are compared with JCPDS data; it indicated the formation of single phase cubic spinel ferrite structure. The spectra are found to possess well defined intense and sharp peaks. In the case of Sm substituted bulk size ferrites; the XRD spectra shows the increase of prominent peaks $(220 ; 311 ; 400 ; 333$ and 522) intensity with the rise of Sm concentration and found to decrease at higher concentration of Sm indicating the limited solubility of samarium at its higher values. But the peaks $111 ; 310 ; 430$ and 440 found to increase their intensity continuously with the rise of $\mathrm{Sm}$ concentration. For the $\mathrm{Zr}$ substituted ferrites reflections of planes are showing no much variation in the peaks intensity for both bulk and nano size materials. For these materials 211 and 310 peaks are resolved at higher $\mathrm{Zr}$ substitution.

Crystalline size (D) of all the samples are computed by using the Debye-Scherrer formula $^{23} ; \mathrm{D}=0.94 \lambda /(\beta \cos \theta)$; where $\lambda$ is wavelength of used $\mathrm{x}$-ray; $\beta$ is Full Width at Half Maxima (FWHM in radians) of the strongest reflection exhibited peak (311) and $\theta=$ peak position. Inter planer spacing (d), particle size (D), Nelson Riley function $F(\theta)$ for bulk as well as nano size ferrites are tabulated in the Tables 3 and 4 respectively. From these tables one can observe that the inter-planer-spacing of the samples are in the range of $2.50 \mu \mathrm{m}$ to $2.69 \mu \mathrm{m}$., particle size of the prepared samples are in the range of $1.45 \mu \mathrm{m}$ to $1.48 \mu \mathrm{m}$. General trend of obtained inter planer spacing (d) and Nelson Riley function $F(\theta)$ values seems to have an increase with substituent concentration (x) for both bulk and nano size materials But particle size (D) found to increase with the rise of Sm content; further it decreases at $\mathrm{Sm}=0.50$ and for $\mathrm{Zr}$ substituted ferrite no proper trend is observed.

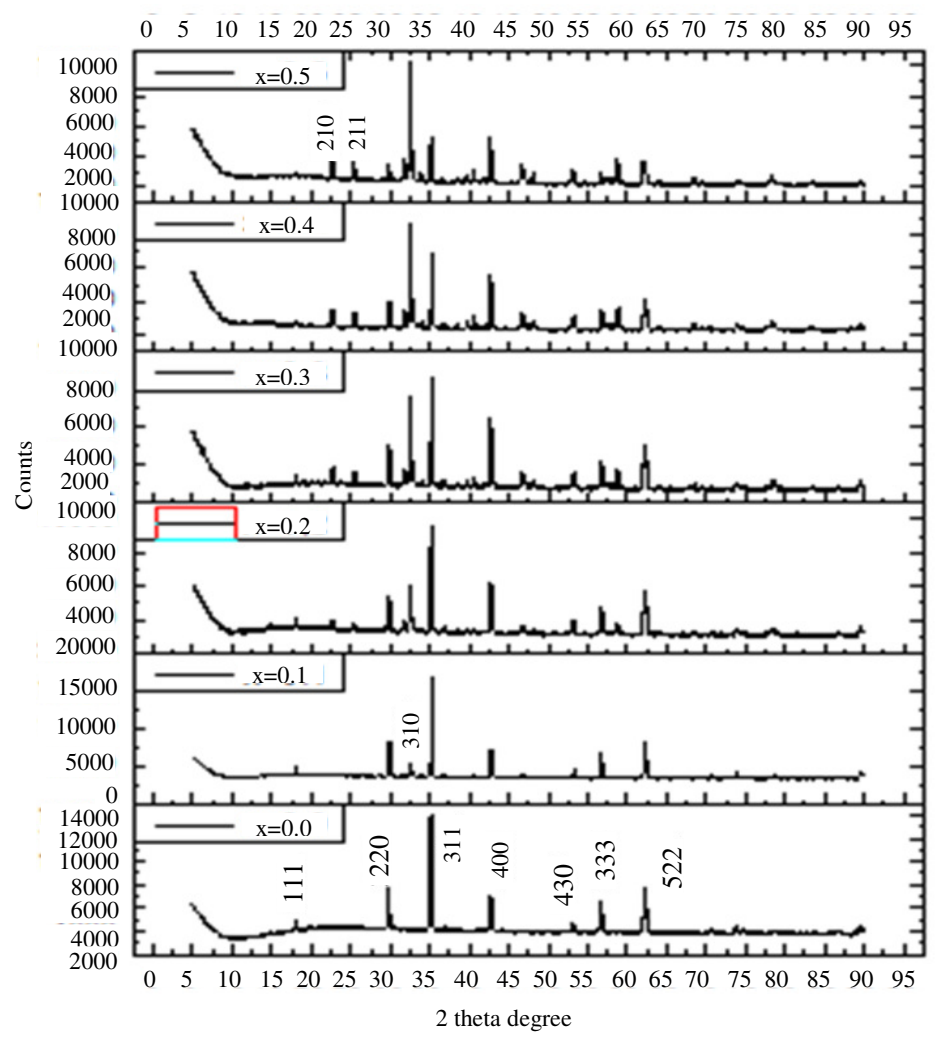

Figure 1. XRD Spectra of Sm substituted Mg-Mn ferrite samples (Bulk size) 


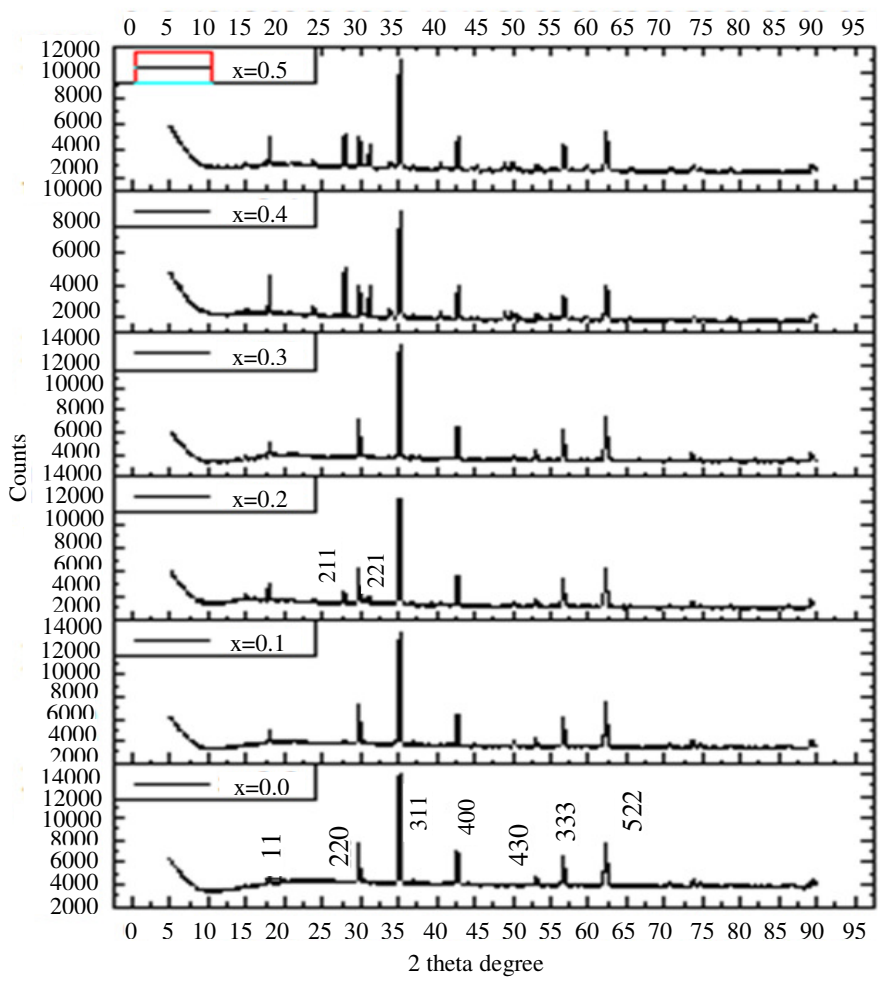

Figure 2. XRD specta of $\mathrm{Zr}$ substituted Mg-Mn ferrite samples (Bulk size)

Table 3. Variation of inter planer spacing (d), particle size (D), Nelson Riley function $F(\theta)$ with substituent concentration (x) for bulk size ferrites

\begin{tabular}{ccccccc}
\hline Conc. & \multicolumn{3}{c}{ Sm substituted } & \multicolumn{3}{c}{ Zr substituted } \\
\cline { 2 - 7 }$(\mathrm{x})$ & $\mathrm{d}, \mu \mathrm{m}$ & $\mathrm{D}, \mu \mathrm{m}$ & $\mathrm{F}(\theta)$ & $\mathrm{d}, \mu \mathrm{m}$ & $\mathrm{D}, \mu \mathrm{m}$ & $\mathrm{F}(\theta)$ \\
\hline 0.0 & 2.508 & 1.451 & 2.087 & 2.508 & 1.451 & 2.087 \\
0.1 & 2.055 & 1.458 & 2.093 & 2.634 & 1.473 & 3.050 \\
0.2 & 2.445 & 1.481 & 2.783 & 2.711 & 1.433 & 3.165 \\
0.3 & 2.559 & 1.483 & 2.946 & 2.722 & 1.447 & 3.187 \\
0.4 & 2.573 & 1.482 & 2.965 & 2.693 & 1.351 & 3.146 \\
0.5 & 2.696 & 1.458 & 3.146 & 2.728 & 1.442 & 3.195 \\
\hline
\end{tabular}

Table 4. Variation of inter planer spacing (d), particle size (D), Nelson Riley function $\mathrm{F}(\theta)$ with substituent concentration (x) for nano size materials

\begin{tabular}{ccccccc}
\hline \multirow{2}{*}{ Conc. $(\mathrm{x})$} & \multicolumn{3}{c}{ Sm substituted } & \multicolumn{3}{c}{ Zr substituted } \\
\cline { 2 - 7 } & $\mathrm{d}, \mu \mathrm{m}$ & $\mathrm{D}, \mu \mathrm{m}$ & $\mathrm{F}(\theta)$ & $\mathrm{d}, \mu \mathrm{m}$ & $\mathrm{D}, \mu \mathrm{m}$ & $\mathrm{F}(\theta)$ \\
\hline 0.0 & 2.513 & 1.450 & 2.878 & 2.51 & 1.450 & 2.878 \\
0.1 & 2.578 & 1.558 & 2.981 & 2.63 & 1.564 & 3.038 \\
0.2 & 2.625 & 1.557 & 3.046 & 2.66 & 1.557 & 3.098 \\
0.3 & 2.672 & 1.555 & 3.110 & 2.70 & 1.549 & 3.157 \\
0.4 & 2.850 & 1.472 & 3.359 & 2.72 & 1.496 & 3.176 \\
0.5 & 3.028 & 1.389 & 3.608 & 2.73 & 1.442 & 3.194 \\
\hline
\end{tabular}


Variation of lattice constant (a) as a function of substituent concentration (x) for bulk materials is shown in the Figure 3 while the same is depicted in the Figure 4 for nano size materials. The values of the nano size materials are found to show lower values relative to bulk size as tabulated in tables 5 and 6 of $\mathrm{Sm}$ and $\mathrm{Zr}$ substituted ferrites respectively. The obtained lattice constant (a) $8.78 \AA$ value of pure $\mathrm{Mg}$-Mn ferrite shows agreement with the earlier reported ${ }^{24}$ value $8.34 \AA$ with a little deviation; which may be attributed to the difference in the preparative conditions of the materials. The observed increase of lattice constant for $\mathrm{Sm}^{3+}$ substituted ferrites can be attributed to its higher ionic radius $(0.0964 \mathrm{~nm})$ relative to the ionic radius $(0.0645 \mathrm{~nm})$ of the replaced $\mathrm{Fe}^{3+}$ ion. $\mathrm{Sm}^{3+}$ ions are expected to enter into octahedral sites resulting internal stress causing crystal distortion that enhanced unit cell size. Similar type of behavior was reported earlier for Sm substituted cobalt ferrites ${ }^{17}$. Attained higher values $(\geq 9.004 \AA)$ of lattice constant for higher concentration of Sm can be understood on the lines of earlier investigation reported ${ }^{25}$ for $\mathrm{Sm}$ doped Ni-Cd ferrites in which lattice constant was found to be $\geq 9.056 \AA$. Substitution of $\mathrm{Zr}$ (ionic radius $0.0730 \mathrm{~nm}$ ) at the expense of $\mathrm{Fe}^{3+}(0.0645 \mathrm{~nm})$ expected to increase lattice constant value, but the decrease of obtained lattice constant (a) with the rise of $\mathrm{Zr}$ concentration may be due to the higher attraction force of oxygen ions for tetravalent $\left(\mathrm{Zr}^{4+}\right)$ ions relative trivalent $\left(\mathrm{Fe}^{3+}\right)$ ions as observed earlier for $\mathrm{Zr}^{4+}$ substituted $\mathrm{Li}-\mathrm{Zn}$ ferrites ${ }^{26}$.

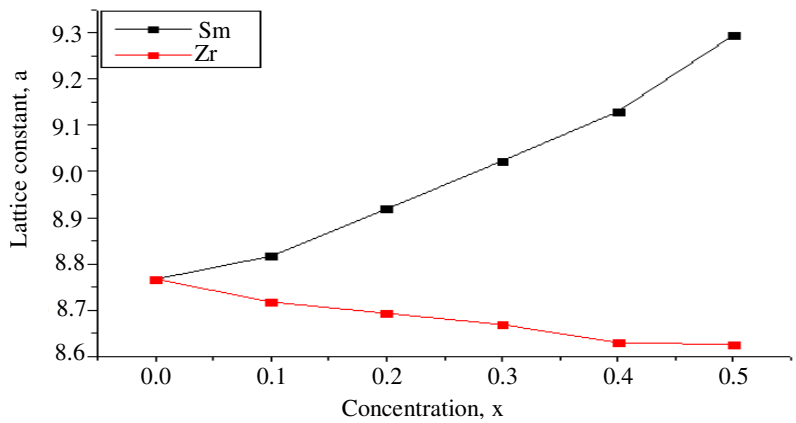

Figure 3. Variation of lattice constant (a) ( $\mathrm{A}$ ) with substituent concentration (Bulk size)

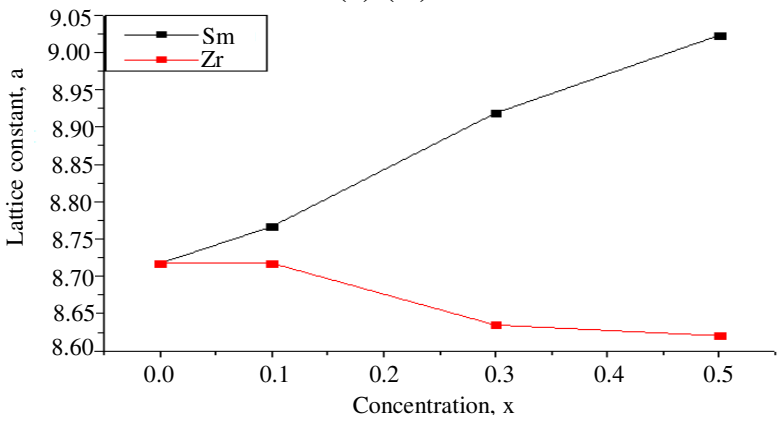

Figure 4. Variation of lattice constant (a) ( $\mathrm{A}$ ) with substituent concentration (Nano size)

\section{Ionic radii by XRD analysis}

For all ferrite materials computation of $\mathrm{A}$ and $\mathrm{B}$ sites ionic radius values are performed by using XRD data as given below ${ }^{27-30}$. Ionic radius of the tetrahedral site, $\Gamma_{\mathrm{A}}=\mathrm{a} \sqrt{3}(u-0.25)-\mathrm{r}$ and octahedral site, $\Gamma_{\mathrm{B}}=\mathrm{a}\left[\frac{5}{8}-\mathrm{u}\right]-\mathrm{r}$ where $\mathrm{a}$ is the lattice parameter obtained by XRD spectrum 
of respective ferrite sample, $r$ indicates radius of the oxygen ion $1.38 \AA$ and $u$ represents oxygen positional parameter, $u=3 / 8=0.375$. Thus $r_{A}$ and $r_{B}$ values are obtained as presented in the Tables 5 and 6 for $\mathrm{Sm}$ and $\mathrm{Zr}$ ferrites respectively.

Table 5. Lattice parameter and Ionic radii of Sm substituted Mg-Mn ferrite

\begin{tabular}{|c|c|c|c|c|c|c|}
\hline \multirow{2}{*}{$\begin{array}{l}\text { Conc } \\
\text { (x) }\end{array}$} & \multicolumn{2}{|c|}{ Lattice parameter } & \multicolumn{2}{|c|}{$\begin{array}{c}\text { Ionic radius from } \\
\text { XRD } \\
\end{array}$} & \multicolumn{2}{|c|}{$\begin{array}{l}\text { Ionic radius from } \\
\text { cation distribution }\end{array}$} \\
\hline & $\mathrm{a}_{\mathrm{th}}(\AA)$ & $\mathrm{a}_{\text {expt }(\AA)}$ & $\mathrm{r}_{\mathrm{A}}{ }^{\mathrm{IV}}(\AA)$ & $\mathrm{r}_{\mathrm{A}}^{\mathrm{VI}}(\AA)$ & $\mathrm{r}_{\mathrm{B}}{ }^{\mathrm{iV}}(\AA)$ & $\mathrm{r}_{\mathrm{B}}^{\mathrm{VI}}(\AA)$ \\
\hline 0.0 & 8.789 & 8.767 & 0.583 & 0.877 & 0.706 & 0.717 \\
\hline 0.1 & 8.851 & 8.817 & 0.596 & 0.893 & 0.697 & 0.761 \\
\hline 0.2 & 9.004 & 8.919 & 0.629 & 0.931 & 0.688 & 0.805 \\
\hline 0.3 & 9.110 & 9.023 & 0.652 & 0.957 & 0.679 & 0.849 \\
\hline 0.4 & 9.215 & 9.129 & 0.675 & 0.984 & 0.670 & 0.892 \\
\hline 0.5 & 9.310 & 9.294 & 0.696 & 1.007 & 0.661 & 0.936 \\
\hline
\end{tabular}

Table 6. Lattice parameter and Ionic radii of $\mathrm{Zr}$ substituted $\mathrm{Mg}-\mathrm{Mn}$ ferrite

\begin{tabular}{ccccccc}
\hline \multirow{2}{*}{ Conc $(\mathrm{x})$} & \multicolumn{2}{c}{ Lattice parameter } & \multicolumn{2}{c}{ Ionic radius from XRD } & \multicolumn{2}{c}{$\begin{array}{c}\text { Ionic radius from } \\
\text { cation distribution }\end{array}$} \\
\cline { 2 - 7 } & $\mathrm{a}_{\mathrm{th}}(\AA)$ & $\mathrm{a}_{\text {expt }(\AA)}$ & $\mathrm{r}_{\mathrm{A}}{ }^{\mathrm{IV}}(\AA)$ & $\mathrm{r}_{\mathrm{B}}{ }^{\mathrm{VI}}(\AA)$ & $\mathrm{r}_{\mathrm{B}}{ }^{\mathrm{V}}(\AA)$ & $\mathrm{r}_{\mathrm{B}}{ }^{\mathrm{VI}}(\AA)$ \\
\hline 0.0 & 8.789 & 8.767 & 0.583 & 0.877 & 0.706 & 0.717 \\
0.1 & 8.782 & 8.718 & 0.581 & 0.876 & 0.698 & 0.719 \\
0.2 & 8.776 & 8.693 & 0.580 & 0.874 & 0.690 & 0.721 \\
0.3 & 8.770 & 8.669 & 0.579 & 0.872 & 0.682 & 0.722 \\
0.4 & 8.763 & 8.630 & 0.577 & 0.871 & 0.674 & 0.724 \\
0.5 & 8.757 & 8.625 & 0.576 & 0.869 & 0.666 & 0.726 \\
\hline
\end{tabular}

\section{Estimation of cation distribution}

Spinel ferrite having the formula $\mathrm{MeFe}_{2} \mathrm{O}_{4}$ contains two types of sites, (1) Tetrahedral (A) site and (2) Octahedral (B) site. The distribution of the cations ${ }^{27}$ over these two sites can be expressed as $\left[\mathrm{MeFe}_{1-\delta}\right]^{\mathrm{A}}\left[\mathrm{Me}_{1-\delta} \mathrm{Fe}_{1+\delta}\right]^{\mathrm{B}} \mathrm{O}_{4}$. The ions distributed on tetrahedral (A) and octahedral (B) sites are shown in the parenthesis and square brackets respectively. Where $\delta$ is a constant, which can determine the cation distribution. The proposed cation distribution for the chemical compositions is $\mathrm{Mg}_{0.95} \mathrm{Mn}_{0.05} \mathrm{Sm}_{2 \mathrm{x}} \mathrm{Fe}_{2-2 \mathrm{x}} \mathrm{O}_{4}$ and $\mathrm{Mg}_{0.95} \mathrm{Mn}_{0.05+\mathrm{x}} \mathrm{Zr}_{\mathrm{x}} \mathrm{Fe}_{2-2 \mathrm{x}} \mathrm{O}_{4}$; where $\mathrm{x}$ varies from 0.0 to 0.5 in steps of 0.1 . The proposed cation distributions of the present studies are shown in the Tables 7 and 8 for $\mathrm{Sm}$ and $\mathrm{Zr}$ substituted ferrites respectively.

Table 7. Cation distribution of Sm substituted $\mathrm{Mg}-\mathrm{Mn}$ ferrites

\begin{tabular}{|c|c|c|c|c|}
\hline $\begin{array}{l}\text { S. } \\
\text { No. }\end{array}$ & $\begin{array}{c}\text { Conc. } \\
\text { (x) }\end{array}$ & Chemical composition & A-site & B-site \\
\hline 1 & 0 & $\mathrm{Mg}_{0.95} \mathrm{Mn}_{0.05} \mathrm{Sm}_{0.0} \mathrm{Fe}_{2.0} \mathrm{O}_{4}$ & $\mathrm{Mg}_{0.95} \mathrm{Mn}_{0.0} \mathrm{Fe}_{0.05}$ & $\mathrm{Mg}_{0.0} \mathrm{Mn}_{0.05} \mathrm{Sm}_{0.0} \mathrm{Fe}_{1.95}$ \\
\hline 2 & 0.1 & $\mathrm{Mg}_{0.95} \mathrm{Mn}_{0.05} \mathrm{Sm}_{0.2} \mathrm{Fe}_{1.8} \mathrm{O}_{4}$ & $\mathrm{Mg}_{0.85} \mathrm{Mn}_{0.01} \mathrm{Fe}_{0.14}$ & $\mathrm{Mg}_{0.1} \mathrm{Mn}_{0.04} \mathrm{Sm}_{0.2 .} \mathrm{Fe}_{1.66}$ \\
\hline 3 & 0.2 & $\mathrm{Mg}_{0.95} \mathrm{Mn}_{0.05} \mathrm{Sm}_{0.4} \mathrm{Fe}_{1.6} \mathrm{O}_{4}$ & $\mathrm{Mg}_{0.75} \mathrm{Mn}_{0.02} \mathrm{Fe}_{0.23}$ & $\mathrm{Mg}_{0.2} \mathrm{Mn}_{0.03} \mathrm{Sm}_{0.4} \mathrm{Fe}_{1.37}$ \\
\hline 4 & 0.3 & $\mathrm{Mg}_{0.95} \mathrm{Mn}_{0.05} \mathrm{Sm}_{0.6} \mathrm{Fe}_{1.4} \mathrm{O}_{4}$ & $\mathrm{Mg}_{0.65} \mathrm{Mn}_{0.03} \mathrm{Fe}_{0.32}$ & $\mathrm{Mg}_{0.3} \mathrm{Mn}_{0.02} \mathrm{Sm}_{0.6} \mathrm{Fe}_{1.08}$ \\
\hline 5 & 0.4 & $\mathrm{Mg}_{0.95} \mathrm{Mn}_{0.05} \mathrm{Sm}_{0.8} \mathrm{Fe}_{1.2} \mathrm{O}_{4}$ & $\mathrm{Mg}_{0.55} \mathrm{Mn}_{0.04} \mathrm{Fe}_{0.41}$ & $\mathrm{Mg}_{0.4} \mathrm{Mn}_{0.01} \mathrm{Sm}_{0.8} \mathrm{Fe}_{0.79}$ \\
\hline 6 & 0.5 & $\mathrm{Mg}_{0.95} \mathrm{Mn}_{0.05} \mathrm{Sm}_{1.0} \mathrm{Fe}_{1.0} \mathrm{O}_{4}$ & $\mathrm{Mg}_{0.45} \mathrm{Mn}_{0.05} \mathrm{Fe}_{0.50}$ & $\mathrm{Mg}_{0.5} \mathrm{Mn}_{0.00} \mathrm{Sm}_{1.0} \mathrm{Fe}_{0.50}$ \\
\hline
\end{tabular}


Table 8. Cation distribution for $\mathrm{Zr}$ substituted $\mathrm{Mg}-\mathrm{Mn}$ ferrites

\begin{tabular}{cccccc}
\hline $\begin{array}{c}\text { S. } \\
\text { No. }\end{array}$ & $\begin{array}{c}\text { Conc. } \\
\text { (x) }\end{array}$ & Chemical composition & A-site & B-site \\
\hline 1 & 0 & $\mathrm{Mg}_{0.95} \mathrm{Mn}_{0.05} \mathrm{Zr}_{0.0} \mathrm{Fe}_{2.0} \mathrm{O}_{4}$ & $\mathrm{Mg}_{0.95} \mathrm{Mn}_{0.0} \mathrm{Zr}_{0.00} \mathrm{Fe}_{0.05}$ & $\mathrm{Mg}_{0.0} \mathrm{Mn}_{0.05} \mathrm{Zr}_{0.00} \mathrm{Fe}_{1.95}$ \\
2 & 0.1 & $\mathrm{Mg}_{0.95} \mathrm{Mn}_{0.15} \mathrm{Zr}_{0.1} \mathrm{Fe}_{1.8} \mathrm{O}_{4}$ & $\mathrm{Mg}_{0.85} \mathrm{Mn}_{0.05} \mathrm{Zr}_{0.05} \mathrm{Fe}_{0.05}$ & $\mathrm{Mg}_{0.1} \mathrm{Mn}_{0.10} \mathrm{Zr}_{0.05} \mathrm{Fe}_{1.75}$ \\
3 & 0.2 & $\mathrm{Mg}_{0.95} \mathrm{Mn}_{0.25} \mathrm{Zr}_{0.2} \mathrm{Fe}_{1.6} \mathrm{O}_{4}$ & $\mathrm{Mg}_{0.75} \mathrm{Mn}_{0.10} \mathrm{Zr}_{0.10} \mathrm{Fe}_{0.05}$ & $\mathrm{Mg}_{0.2} \mathrm{Mn}_{0.15} \mathrm{Zr}_{0.10} \mathrm{Fe}_{1.55}$ \\
4 & 0.3 & $\mathrm{Mg}_{0.95} \mathrm{Mn}_{0.35} \mathrm{Zr}_{0.3} \mathrm{Fe}_{1.4} \mathrm{O}_{4}$ & $\mathrm{Mg}_{0.65} \mathrm{Mn}_{0.15} \mathrm{Zr}_{0.15} \mathrm{Fe}_{0.05}$ & $\mathrm{Mg}_{0.3} \mathrm{Mn}_{0.20} \mathrm{Zr}_{0.15} \mathrm{Fe}_{1.35}$ \\
5 & 0.4 & $\mathrm{Mg}_{0.95} \mathrm{Mn}_{0.45} \mathrm{Zr}_{0.4} \mathrm{Fe}_{1.2} \mathrm{O}_{4}$ & $\mathrm{Mg}_{0.55} \mathrm{Mn}_{0.20} \mathrm{Zr}_{0.20} \mathrm{Fe}_{0.05}$ & $\mathrm{Mg}_{0.4} \mathrm{Mn}_{0.25} \mathrm{Zr}_{0.2} \mathrm{Fe}_{1.15}$ \\
6 & 0.5 & $\mathrm{Mg}_{0.95} \mathrm{Mn}_{0.55} \mathrm{Zr}_{0.5} \mathrm{Fe}_{1.0} \mathrm{O}_{4}$ & $\mathrm{Mg}_{0.45} \mathrm{Mn}_{0.25} \mathrm{Zr}_{0.25} \mathrm{Fe}_{0.05}$ & $\mathrm{Mg}_{0.5} \mathrm{Mn}_{0.30} \mathrm{Zr}_{0.25} \mathrm{Fe}_{0.95}$ \\
\hline
\end{tabular}

Based on cation distribution that mentioned above; theoretically lattice parameter has been evaluated by using the formula reported by earlier investigators ${ }^{27-30}$ is

$$
\mathrm{a}_{\mathrm{th}}=\left[\left(\mathrm{r}_{\mathrm{A}}{ }^{\mathrm{iv}}+\mathrm{r}\right)+\left(\mathrm{r}_{\mathrm{B}}^{\mathrm{vi}}+\mathrm{r}\right)\right]
$$

Where $\mathrm{r}_{\mathrm{A}}{ }^{\mathrm{iv}}=\mathrm{xr}_{\mathrm{Mg}}{ }^{\mathrm{iv}}+\mathrm{y} \mathrm{r}_{\mathrm{Mn}}{ }^{\mathrm{iv}}+\mathrm{zr}_{\mathrm{M}}{ }^{\mathrm{iv}}+(1-\mathrm{x}-\mathrm{y}-\mathrm{z}) \mathrm{r}_{\mathrm{Fe}}{ }^{\mathrm{iv}}$ and $\mathrm{r}_{\mathrm{B}}{ }^{\mathrm{vi}}=\mathrm{xr}_{\mathrm{Mg}}{ }^{\mathrm{vi}}+\mathrm{yr}_{\mathrm{Mn}}{ }^{\mathrm{vi}}+\mathrm{zr}_{\mathrm{M}}{ }^{\mathrm{vi}}+$ $(2-\mathrm{x}-\mathrm{y}-\mathrm{z}) \mathrm{r}_{\mathrm{Fe}}{ }^{\mathrm{vi}}$; are ionic radius at $\mathrm{A}$ and $\mathrm{B}$ sites respectively, $\mathrm{M}$ is substituent elements $\mathrm{Sm}$ or $\mathrm{Zr} ; \mathrm{x}, \mathrm{y}$ and $\mathrm{z}$ are concentrations of $\mathrm{Mg}, \mathrm{Mn}$ and substituent elements; $\mathrm{r}$ is radius of oxygen ion $(1.38 \AA$ ) . Further oxygen positional parameter also been computed with the formula,

$$
\mathrm{u}=\frac{\left(\frac{\mathrm{R}^{2}}{4}-\frac{2}{3}\right)+\sqrt{\left(\frac{11 R^{2}}{48}-\frac{1}{18}\right)}}{\left(2 R^{2}-2\right)}+\frac{1}{4}
$$

Where $\mathrm{R}=$ bond length ratio $=$ octahedral to tetrahedral bond lengths $=\mathrm{R}_{\mathrm{A}}{ }^{\mathrm{iv}} / \mathrm{R}_{\mathrm{B}}{ }^{\mathrm{vi}}$, $\mathrm{R}_{\mathrm{A}}{ }^{\mathrm{iv}}=$ tetrahedral bond length $=\mathrm{r}_{\mathrm{A}}+\mathrm{r}, \mathrm{R}_{\mathrm{B}}{ }^{\mathrm{vi}}=$ octahedral bond length $=\mathrm{r}_{\mathrm{B}}+\mathrm{r}$

The tetrahedral and octahedral bond lengths are calculated and tabulated in the Tables 9 and 10 for $\mathrm{Sm}$ and $\mathrm{Zr}$ substituted $\mathrm{Mg}-\mathrm{Mn}$ ferrites.

Table 9. Bond length $\left(\mathrm{R}^{\mathrm{IV}} \& \mathrm{R}^{\mathrm{VI}}\right)$; bond length ratio $(\mathrm{R})$ and oxygen positional parameter $(\mathrm{u})$ values of Sm substituted Mg-Mn ferrites

\begin{tabular}{ccccc}
\hline Conc & \multicolumn{4}{c}{ Sm substituted ferrites } \\
\cline { 2 - 5 }$(\mathrm{x})$ & $\mathrm{R}^{\mathrm{IV}}(\AA)$ & $\mathrm{R}^{\mathrm{VI}}(\AA)$ & $\mathrm{R}$ & $\mathrm{U}$ \\
\hline 0.0 & 2.086 & 2.097 & 1.005 & 0.387 \\
0.1 & 2.077 & 2.141 & 1.031 & 0.385 \\
0.2 & 2.068 & 2.185 & 1.056 & 0.383 \\
0.3 & 2.059 & 2.228 & 1.082 & 0.381 \\
0.4 & 2.050 & 2.272 & 1.109 & 0.378 \\
0.5 & 2.041 & 2.316 & 1.135 & 0.376 \\
\hline
\end{tabular}

Table 10. Bond length $\left(\mathrm{R}^{\mathrm{IV}} \& \mathrm{R}^{\mathrm{VI}}\right)$; bond length ratio $(\mathrm{R})$ and oxygen positional parameter $(\mathrm{u})$ values of $\mathrm{Zr}$ substituted $\mathrm{Mg}-\mathrm{Mn}$ ferrites

\begin{tabular}{ccccc}
\hline \multirow{2}{*}{$\begin{array}{c}\text { Conc } \\
(\mathrm{x})\end{array}$} & \multicolumn{4}{c}{ Zr substituted ferrites } \\
\cline { 2 - 5 } $\mathrm{R}^{\mathrm{IV}}(\AA)$ & $\mathrm{R}^{\mathrm{V}}(\AA)$ & $\mathrm{R}$ & $\mathrm{U}$ \\
\hline 0.0 & 2.086 & 2.097 & 1.005 & 0.387 \\
0.1 & 2.078 & 2.099 & 1.011 & 0.387 \\
0.2 & 2.071 & 2.101 & 1.015 & 0.387 \\
0.3 & 2.062 & 2.102 & 1.021 & 0.386 \\
0.4 & 2.054 & 2.104 & 1.025 & 0.385 \\
0.5 & 2.046 & 2.106 & 1.029 & 0.385 \\
\hline
\end{tabular}


By using cation distribution and theoretically evaluated lattice parameter $\left(a_{t h}=a\right)$ values; inter ionic distance ${ }^{27}$ are computed. They are cation-anion distances at A-site, $\mathrm{d}_{\mathrm{AL}}=$ $\mathrm{a}(\mathrm{u}-0.25)$ and cation-anion distances at B-site, $\mathrm{d}_{\mathrm{BL}}=\mathrm{a}\left(3 \mathrm{u}^{2}-\mathrm{u}+\right)^{1 / 2}, \mathrm{~d}_{\mathrm{BL}}=$ distance of closest anion-anion approach (tetrahedral edge), $\mathrm{d}_{\mathrm{AE}}=\mathrm{a}-0.5$ and shared octahedral edges (inter sites in tetrahedral site and with shared octahedral sites, $d_{\mathrm{BE}}=\mathrm{a}(1-2 \mathrm{u})$; unshared octahedral edge (inter sites in tetrahedral and unshared octahedral sites), $\mathrm{d}_{\mathrm{BEU}}=\mathrm{a}\left[4 \mathrm{u}^{2}-3 \mathrm{u}+\right]^{1 / 2}$; distance between the magnetic ions at $\mathrm{A}-\mathrm{site}^{27} ; \mathrm{L}_{\mathrm{A}}=\mathrm{a} / 4$, distance between the magnetic ions at $\mathrm{B}$-site; $\mathrm{L}_{\mathrm{B}}=\mathrm{a} / 4$. The values of cation-anion distances, magnetic ions distances at $\mathrm{A}$ and $\mathrm{B}$ sites are tabulated in Tables 11 and 12 for Sm and $\mathrm{Zr}$ ferrites respectively.

Table 11. Cation-anion distances at A-site $\left(\mathrm{d}_{\mathrm{AL}}\right)$ and cation-anion distances at B-site $\left(\mathrm{d}_{\mathrm{BL}}\right)$; tet-edge $\left(\mathrm{d}_{\mathrm{AE}}\right)$, inter sites in tetrahedral site with shared octahedral sites $\left(\mathrm{d}_{\mathrm{BE}}\right)$, tetrahedral sites and unshared octahedral sites $\left(\mathrm{d}_{\mathrm{BEU}}\right)$, distance between the magnetic ions at A-site $\left(\mathrm{L}_{\mathrm{A}}\right)$ and B-site $\left(\mathrm{L}_{\mathrm{B}}\right)$ of Sm substituted $\mathrm{Mg}-\mathrm{Mn}$ ferrite

\begin{tabular}{cccccccc}
\hline Conc & $\mathrm{d}_{\mathrm{AL}}$ & $\mathrm{d}_{\mathrm{BL}}$ & $\mathrm{d}_{\mathrm{AE}}$ & $\mathrm{d}_{\mathrm{BE}}$ & $\mathrm{d}_{\mathrm{BEU}}$ & $\mathrm{L}_{\mathrm{A}}$ & $\mathrm{L}_{\mathrm{B}}$ \\
\cline { 2 - 8 }$(\mathrm{x})$ & $(\AA)$ & $(\AA)$ & $(\AA)$ & $(\AA)$ & $(\AA)$ & $(\AA)$ & $(\AA)$ \\
\hline 0.0 & 2.086 & 2.097 & 3.406 & 1.088 & 3.114 & 3.806 & 3.107 \\
0.1 & 2.046 & 2.141 & 3.34 & 1.101 & 3.133 & 3.833 & 3.129 \\
0.2 & 2.068 & 2.185 & 3.377 & 1.121 & 3.186 & 3.899 & 3.183 \\
0.3 & 2.059 & 2.229 & 3.362 & 1.137 & 3.222 & 3.945 & 3.221 \\
0.4 & 2.05 & 2.272 & 3.348 & 1.151 & 3.259 & 3.991 & 3.258 \\
0.5 & 2.041 & 2.313 & 3.333 & 1.164 & 3.292 & 4.031 & 3.292 \\
\hline
\end{tabular}

Table 12. Cation-anion distances at A-site $\left(\mathrm{d}_{\mathrm{AL}}\right)$ and cation-anion distances at $\mathrm{B}$-site $\left(\mathrm{d}_{\mathrm{BL}}\right)$; tet-edge $\left(\mathrm{d}_{\mathrm{AE}}\right)$,inter sites in tetrahedral site with shared octahedral sites $\left(\mathrm{d}_{\mathrm{BE}}\right)$, tetrahedral site and unshared octahedral sites $\left(\mathrm{d}_{\mathrm{BEU}}\right)$, distance between the magnetic ions at A-site $\left(\mathrm{L}_{\mathrm{A}}\right)$ and B-site $\left(\mathrm{L}_{\mathrm{B}}\right)$ of $\mathrm{Zr}$ doped $\mathrm{Mg}-\mathrm{Mn}$ ferrite

\begin{tabular}{cccccccc}
\hline \multirow{2}{*}{$\begin{array}{c}\text { Conc } \\
(\mathrm{x})\end{array}$} & $\mathrm{d}_{\mathrm{AL}}$ & $\mathrm{d}_{\mathrm{BL}}$ & $\mathrm{d}_{\mathrm{AE}}$ & $\mathrm{d}_{\mathrm{BE}}$ & $\mathrm{d}_{\mathrm{BEU}}$ & $\mathrm{L}_{\mathrm{A}}$ & $\mathrm{L}_{\mathrm{B}}$ \\
\cline { 2 - 8 } & $(\AA)$ & $(\AA)$ & $(\AA)$ & $(\AA)$ & $(\AA)$ & $(\AA)$ & $(\AA)$ \\
\hline 0.0 & 2.086 & 2.097 & 3.406 & 1.088 & 3.115 & 3.806 & 3.107 \\
0.1 & 2.078 & 2.099 & 3.393 & 1.088 & 3.112 & 3.803 & 3.105 \\
0.2 & 2.071 & 2.101 & 3.381 & 1.088 & 3.109 & 3.801 & 3.103 \\
0.3 & 2.062 & 2.102 & 3.367 & 1.088 & 3.106 & 3.797 & 3.101 \\
0.4 & 2.054 & 2.104 & 3.354 & 1.088 & 3.104 & 3.795 & 3.098 \\
0.5 & 2.046 & 2.106 & 3.341 & 1.088 & 3.101 & 3.792 & 3.096 \\
\hline
\end{tabular}

\section{EDAX analysis}

In order to verify the chemical compositions of those materials undertaken in the present studies are performed for quantitative analysis of elements by EDAX (Energy dispersive analysis of X-rays). The obtained EDAX pattern for one of the series (for Sm ferrites) is shown in the Figure 5. The obtained values of element weight $\%$ and atomic weight $\%$ are presented along with EDAX weight $\%$ in Tables 13 and 14. The quantity of Sm, Zr, Mg, $\mathrm{Mn}, \mathrm{Zn}, \mathrm{Fe}$ and $\mathrm{O}$ elements found to be good as element weight $\%$ and EDAX weight $\%$ values are close each other. The results of EDAX confirm the expected stoichiometry. The compounds show presence of individual elements related to the respective ferrite sample without precipitating cations. 


\section{Micro structure}

Morphological study of materials facilitates to understand microstructure and its related parameters such as average grain size and the type of grain growth that influence magnetic and electrical properties of those materials. The obtained micrographs (photographs) of materials due to scanning electron microscope (SEM) for one of series related to the present ferrites (Sm substituted ferrites) are shown in the Figure 6 for bulk size particles related materials. These photographs exhibit a homogenous grain distribution it is difficult to calculate the accurate grain size as the exact grain boundaries are not distinctly focused because the grain size not in spherical shape but it is just like a plane. However, from these photographs average grain size values of all the materials are determined and given in the Table 15 along with the values obtained due to XRD and TEM techniques.

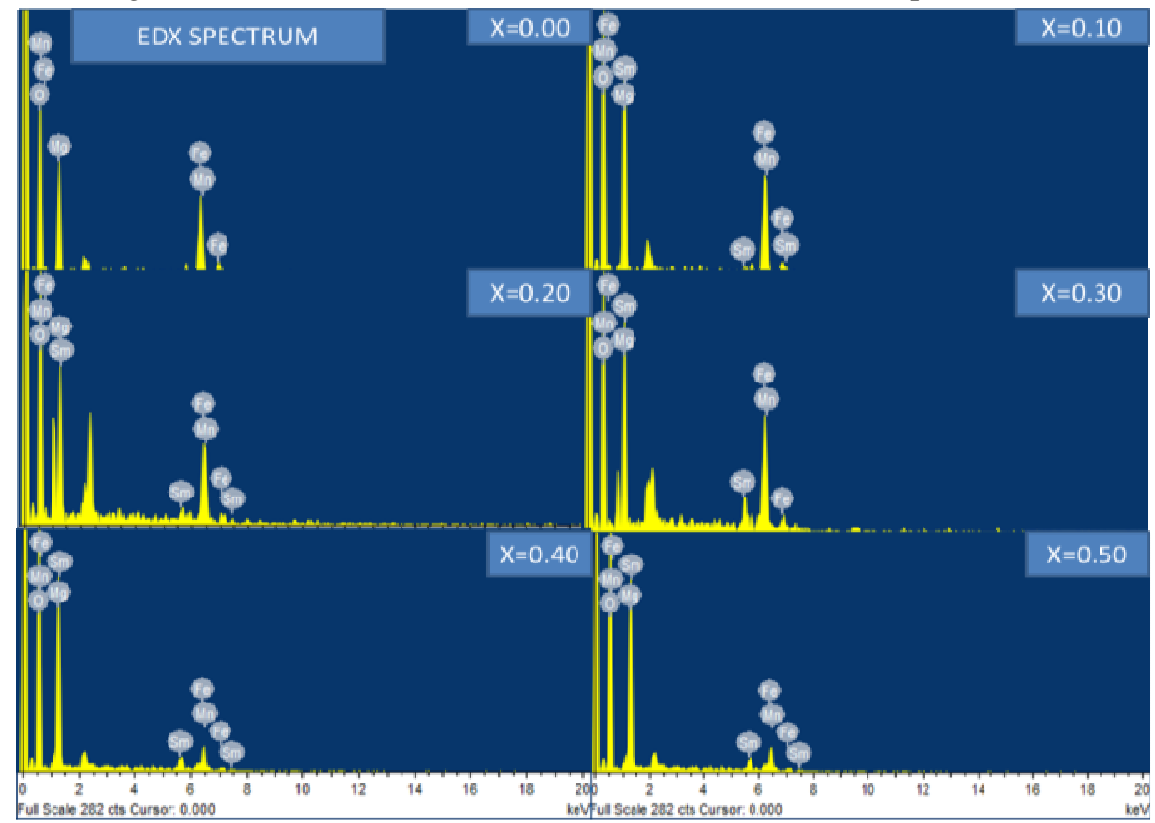

Figure 5. EDX spectrum of $\mathrm{Mg}_{0.95} \mathrm{Mn}_{0.05} \mathrm{Sm}_{2 \mathrm{x}} \mathrm{Fe}_{2-2 \mathrm{x}} \mathrm{O}_{4}$ ferrite

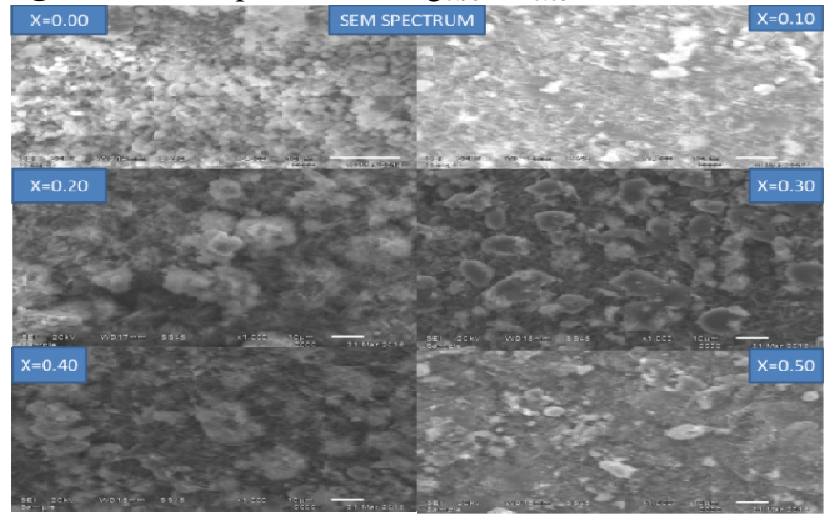

Figure 6. SEM micrographs for the sample (Bulk size) $\mathrm{Mg}_{0.95} \mathrm{Mn}_{0.05} \mathrm{Sm}_{2 \mathrm{x}} \mathrm{Fe}_{2-2 \mathrm{x}} \mathrm{O}_{4}$ at different concentrations 
Table 13. Atomic weight $\%$, Element weight $\%$ and EDAX weight $\%$ of Sm substitute $\mathrm{Mg}$ Mn ferrite

\begin{tabular}{|c|c|c|c|c|c|c|c|c|c|}
\hline Conc (x). & Element & $\begin{array}{l}\text { Atomic } \\
\text { wt } \%\end{array}$ & $\begin{array}{c}\text { Element } \\
\text { wt \% }\end{array}$ & $\begin{array}{l}\text { EDAX } \\
\text { wt \% }\end{array}$ & Conc. & Element & $\begin{array}{l}\text { Atomic } \\
\text { wt \% }\end{array}$ & $\begin{array}{c}\text { Element } \\
\text { wt } \%\end{array}$ & $\begin{array}{l}\text { EDAX } \\
\text { wt \% }\end{array}$ \\
\hline \multirow{5}{*}{$x=0.00$} & $\mathrm{Sm}$ & 0.00 & 0.00 & 0.00 & \multirow{5}{*}{$\mathrm{x}=0.30$} & $\mathrm{Sm}$ & 69.15 & 35.03 & 30.42 \\
\hline & $\mathrm{Mg}$ & 7.04 & 11.46 & 10.38 & & $\mathrm{Mg}$ & 2.84 & 8.93 & 6.92 \\
\hline & $\mathrm{Mn}$ & 1.89 & 1.36 & 0.81 & & $\mathrm{Mn}$ & 0.76 & 1.06 & 0.98 \\
\hline & $\mathrm{Fe}$ & 78.23 & 55.42 & 50.48 & & $\mathrm{Fe}$ & 22.07 & 30.23 & 26.41 \\
\hline & $\mathrm{O}$ & 12.84 & 31.76 & 30.77 & & $\mathrm{O}$ & 5.18 & 24.75 & 21.63 \\
\hline \multirow{5}{*}{$x=0.10$} & $\mathrm{Sm}$ & 38.29 & 13.69 & 10.28 & \multirow{5}{*}{$x=0.40$} & $\mathrm{Sm}$ & 76.91 & 43.51 & 40.52 \\
\hline & $\mathrm{Mg}$ & 4.71 & 10.47 & 9.45 & & $\mathrm{Mg}$ & 2.37 & 8.32 & 6.18 \\
\hline & $\mathrm{Mn}$ & 1.27 & 1.25 & 1.18 & & $\mathrm{Mn}$ & 0.64 & 0.99 & 0.78 \\
\hline & $\mathrm{Fe}$ & 47.14 & 45.58 & 41.62 & & $\mathrm{Fe}$ & 15.78 & 24.14 & 20.72 \\
\hline & $\mathrm{O}$ & 8.61 & 29.02 & 25.38 & & $\mathrm{O}$ & 4.32 & 23.05 & 22.28 \\
\hline \multirow{5}{*}{$x=0.20$} & $\mathrm{Sm}$ & 57.56 & 25.21 & 20.22 & \multirow{5}{*}{$x=0.50$} & $\mathrm{Sm}$ & 82.45 & 50.91 & 47.71 \\
\hline & $\mathrm{Mg}$ & 3.54 & 9.64 & 8.72 & & $\mathrm{Mg}$ & 2.03 & 7.78 & 5.77 \\
\hline & $\mathrm{Mn}$ & 0.95 & 1.15 & 0.98 & & $\mathrm{Mn}$ & 0.55 & 0.92 & 0.67 \\
\hline & $\mathrm{Fe}$ & 31.48 & 37.29 & 30.68 & & $\mathrm{Fe}$ & 11.28 & 18.82 & 15.44 \\
\hline & $\mathrm{O}$ & 6.46 & 26.71 & 21.68 & & $\mathrm{O}$ & 3.71 & 21.57 & 18.25 \\
\hline
\end{tabular}

Table 14. Atomic weight $\%$, Element weight $\%$, EDAX weight $\%$ of $\mathrm{Zr}$ substituted $\mathrm{Mg}-\mathrm{Mn}$ ferrite

\begin{tabular}{|c|c|c|c|c|c|c|c|c|c|}
\hline Conc (x). & Element & $\begin{array}{l}\text { Atomic } \\
\text { wt } \%\end{array}$ & $\begin{array}{c}\text { Element } \\
\text { wt } \%\end{array}$ & $\begin{array}{l}\text { EDAX } \\
\text { wt } \%\end{array}$ & Conc. & Element & $\begin{array}{l}\text { Atomic } \\
\text { wt } \%\end{array}$ & $\begin{array}{c}\text { Element } \\
\text { wt } \%\end{array}$ & $\begin{array}{c}\text { EDAX } \\
\text { wt \% }\end{array}$ \\
\hline \multirow{5}{*}{$x=0.00$} & $\mathrm{Zr}$ & 0.00 & 0.00 & 0.00 & \multirow{5}{*}{$x=0.30$} & $\mathrm{Zr}$ & 37.09 & 12.92 & 10.11 \\
\hline & $\mathrm{Mg}$ & 7.04 & 11.46 & 10.38 & & $\mathrm{Mg}$ & 5.41 & 10.9 & 8.31 \\
\hline & $\mathrm{Mn}$ & 1.89 & 1.36 & 0.81 & & $\mathrm{Mn}$ & 9.48 & 9.08 & 8.18 \\
\hline & $\mathrm{Fe}$ & 78.22 & 55.42 & 50.48 & & $\mathrm{Fe}$ & 39.19 & 36.9 & 30.28 \\
\hline & $\mathrm{O}$ & 12.84 & 31.77 & 30.77 & & $\mathrm{O}$ & 9.19 & 30.21 & 27.84 \\
\hline \multirow{5}{*}{$x=0.10$} & $\mathrm{Zr}$ & 15.26 & 4.45 & 3.03 & \multirow{5}{*}{$x=0.40$} & $\mathrm{Zr}$ & 45.18 & 16.95 & 14.14 \\
\hline & $\mathrm{Mg}$ & 6.22 & 11.25 & 10.36 & & $\mathrm{Mg}$ & 4.60 & 10.72 & 9.38 \\
\hline & $\mathrm{Mn}$ & 5.01 & 4.03 & 2.11 & & $\mathrm{Mn}$ & 11.14 & 11.48 & 10.24 \\
\hline & $\mathrm{Fe}$ & 62.17 & 49.05 & 46.44 & & $\mathrm{Fe}$ & 30.69 & 31.12 & 30.26 \\
\hline & $\mathrm{O}$ & 11.34 & 31.23 & 30.78 & & $\mathrm{O}$ & 8.41 & 29.72 & 25.86 \\
\hline \multirow{5}{*}{$\mathrm{x}=0.20$} & $\mathrm{Zr}$ & 27.32 & 8.75 & 6.61 & \multirow{5}{*}{$x=0.50$} & $\mathrm{Zr}$ & 51.98 & 20.85 & 18.18 \\
\hline & $\mathrm{Mg}$ & 5.57 & 11.08 & 10.28 & & $\mathrm{Mg}$ & 4.24 & 10.56 & 8.24 \\
\hline & $\mathrm{Mn}$ & 7.48 & 6.59 & 5.14 & & $\mathrm{Mn}$ & 12.53 & 13.81 & 10.27 \\
\hline & $\mathrm{Fe}$ & 49.48 & 42.87 & 40.38 & & $\mathrm{Fe}$ & 23.54 & 25.53 & 21.16 \\
\hline & $\mathrm{O}$ & 10.15 & 30.71 & 27.67 & & $\mathrm{O}$ & 7.73 & 29.25 & 26.76 \\
\hline
\end{tabular}

Table 15. Obtained particle size (nm) of $\mathrm{Sm}$ and $\mathrm{Zr}$ substituted $\mathrm{Mg}-\mathrm{Mn}$ ferrites by XRD, SEM and TEM analysis

\begin{tabular}{cccccccc}
\hline \multirow{2}{*}{ S N } & Conc & \multicolumn{2}{c}{ XRD analysis } & \multicolumn{2}{c}{ SEM analysis } & \multicolumn{2}{c}{ TEM analysis } \\
\cline { 3 - 7 } & $(\mathrm{x})$ & Sm ferrite & Zr ferrite & Sm ferrite & Zr ferrite & Sm ferrite & Zr ferrite \\
\hline 1 & 0 & 145.3 & 145.3 & 122.8 & 122.8 & 110.2 & 110.2 \\
2 & 0.1 & 155.9 & 156.5 & 205.5 & 193.5 & 180.4 & 180.2 \\
3 & 0.3 & 155.6 & 154.9 & 129.4 & 153.2 & 120.1 & 140.3 \\
4 & 0.5 & 138.9 & 144.3 & 486.3 & 638.8 & 220.1 & 170.8 \\
\hline
\end{tabular}


The average grain sizes of the present ferrite materials increases due to the substitution of $\mathrm{Sm}^{3+}$. This may be due to the fact that the melting point of $\mathrm{Sm}(1345.15 \mathrm{~K})$ is higher than that of $\mathrm{Mg}$ and $\mathrm{Mn}$; consequently constituent elements show variation in their mobility leading to increase of grain size. The obtained grain size of the materials lies in the nano meter region. These grains are not in spherical shape; however exhibit narrow size distribution. To understand the shape of the particles photographs with transmission electron microscope (TEM) have been taken and these are displayed in the Figure 7. These photographs indicate that the shape of the particles is not in spherical shape and substantiate above mentioned information. Images reveal the overall increase of grain size due to substituents concentration (x) confirming the evidences obtained from XRD analysis too. These images are seemed to show the particles agglomeration causing to show the constituents structure on the order of few nanometers ${ }^{27}$.

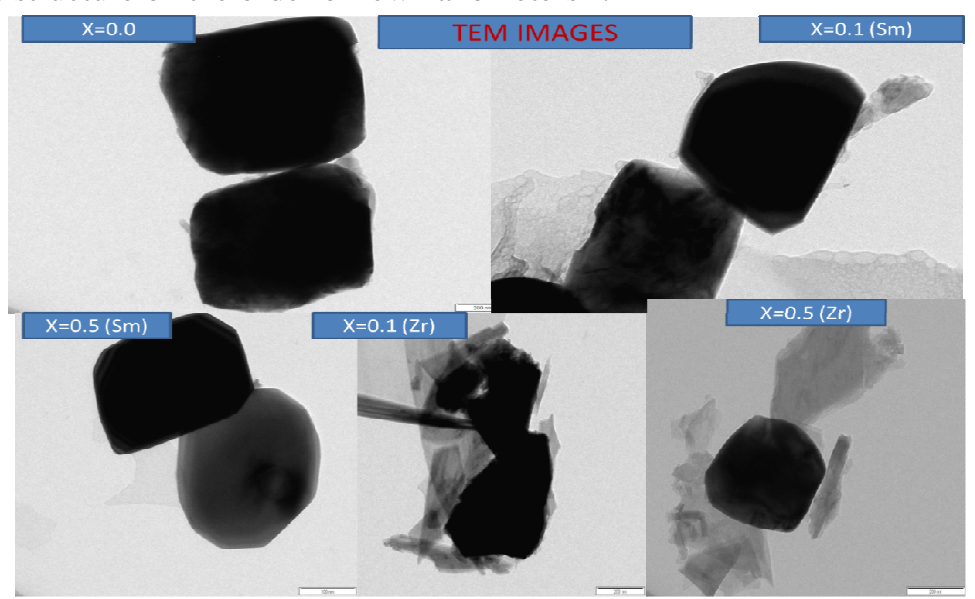

Figure 7. TEM micrographs of the samples $\mathrm{Sm}$ and $\mathrm{Zr}$ substituted $\mathrm{Mg}$-Mn ferrites (Nanoparticle size)

\section{Conclusion}

1. Except at higher values ( $\mathrm{x}$ ) of samarium substitution; density increases as a function of substituent concentration ( $\mathrm{x}$ ) in both the series of ferrite materials.

2. Lattice parameter of Sm substituted ferrites is found to increase with the rise of Sm content while it decreases with the rise of $\mathrm{Zr}$ content. These values obtained due to XRD studies have fair agreement with the theoretically computed values based on the proposed cation distribution. The values of the nano size materials are found to show lower values relative to bulk size.

3. Cation distribution has been validated by comparing several structural parameters those computed by using cation distribution with the values obtained due to XRD studies.

4. Bond length of A-site $\mathrm{d}_{\mathrm{AL}}$ decreases and $\mathrm{B}$-site $\mathrm{d}_{\mathrm{BL}}$ increases as a function of both $\mathrm{Sm}$ and or $\mathrm{Zr}$ concentration. Similarly Hopping length at A-site $\mathrm{L}_{\mathrm{A}}$ and at B-site $\mathrm{L}_{\mathrm{B}}$ decreases with the increase of substituent concentration $(\mathrm{Sm} / \mathrm{Zr})$.

5. Quantitative analysis of constituent elements for every composition of ferrite materials with EDAX pattern has been confirmed the presence of expected stoichiometry.

6. Analysis of SEM and TEM micro photographs data, the grain size found to lie in the range 110-220 nm for Sm substitution while it lies in the range 110-170 nm for $\mathrm{Zr}$ substituted materials. 


\section{References}

1. Kumar S, Kumar R, Dogra A, Reddy V R, Banerjee A and Alimuddin, Indian J Pure Appl Phys., 2007, 45(1), 31-36.

2. Kumar S, Alimuddin, Kumar R, Anjana D, Reddy V R and Banerjee A, J Appl Phys., 2006, 99(8), 08M910; DOI:10.1063/1.2172220

3. Kumar S, Prakash R, Alimuddin, Choi H K, Koo B H, Song J I, Chung H, Jeong H and Lee C G, J Cent South Univ Tech., 2010, 17(6), 1139-1143; DOI:10.1007/s11771-010-0609-y

4. Kumar S, Alimuddin, Kumar R, Thkur P, Chae K H, Basavaraj A and Choi W K, $J$ Phys Cond Matter., 2007, 19(47), 476210; DOI:10.1088/0953-8984/19/47/476210

5. Cheong S W and Mostovo M, Nature Mater., 2007, 6(1), 13-20;

DOI:10.1038/nmat1804

6. Ramesh R and Spaldin N A, Nature Mater., 2007, 6(1), 21-29;

DOI:10.1038/nmat1805

7. Kumar S, Sharma S K, Alimuddin, Knobel M, Choudhary R J, Lee C G, Koo B H and Ravi Kumar, Curr Appl Phys., 2009, 9(5), 1009-1013; DOI:10.1016/j.cap.2008.11.001

8. Sharma S K, Kumar S, Thakur P, Almuddin, Choudhary R J, Phase D M, Meneses C T, Knobel M, Lee C G, Singh M and Ravi Kumar, Thin Solid Films, 2009, 517(8), 27582761; DOI:10.1016/j.tsf.2008.12.011

9. Moshi J Z, Moyo T and Doyle T B, J Magn Magn Mater., 2007, 310(2), 2534-2536; DOI:10.1016/j.jmmm.2006.11.141

10. Kalyan Raju M, Chem Sc Trans., 2015, 4(1), 137-142; DOI:10.7598/cst2015.957

11. Rao B V, Rao A D P and Reddy V R, IJIRSET, 2013, 2, 2319.

12. Rao B V and Rao A D P, $3^{\text {rd }}$ International Symposium on Materials Chemistry, 2010, p 7.

13. Gagan K, Meenakshi K, Chauhan B S and Singh M, Indian J Pure Appl Phys., 2006, 44, 930-934.

14. Kumar S, Kumar R, Thakur P, Chae K H, Sharma S K and Alimuddin, J Magn Magn Mater., 2008, 320(14), e121-e124; DOI:10.1016/j.jmmm.2008.02.035

15. Venkatesh N, Shyam Sunder G, Hari Kumar N, Aravind G, Ravinder D and Somaiah P V, J Appl Chem., 2015, 8, 27.

16. Raghasudha M, Ravinder D and Veerasomaiah P, Adv Mat Phy Chem.., 2013, 3, 8996; DOI:10.4236/ampc.2013.32014

17. Sheena X, Smitha T, Binu P J and Mohammed E M, J Nanoscience, 2013, 524380; DOI:10.1155/2013/524380

18. Chu N and Wang X, Liu Y, Jin H, Wu Q, Li L, Wang Z and Ge H, J Alloy Compd., 2009, 470(1-2), 438-442; DOI:10.1016/j.jallcom.2008.02.095

19. Modi K B, Trivedi U N, Sharma P U, Lakhani V K, Chhantabar M C and Joshi H H, Indian J Pure Appl Phys., 2006, 44, 165-168.

20. X-ray Diffraction spectrometer; https://www.bruker.com/products/X-ray-diffractionand-elemental-analysis/x-ray-diffraction.html

21. Electron Spin Resonance Spectrometry; http://www.speciation.net/Database/Instruments/JEOL/JESFA200-Electron-Spin-Resonance-Spectrometry-;i44 .

22. Transmission Electron Microscope, Model CM 200, http://www.rsic.iitb.ac.in/tem.html

23. Cumbale R C, Sheikah P A, Kamble S S and Kolekar Y D, J Alloy Compd., 2009, 478(1-2) 599-603; DOI:10.1016/j.jallcom.2008.11.101

24. Shyam S G, Venkatesh N, Hari K N, Rambabu B, Somaiah T, Somaiah V, J Appl Chem., 2015, 8, 38. 
25. Batoo K M, Kumar S and Shahnawaze A M, Sci Adv Mat., 2011, 3(1), 120-126; DOI:10.1166/sam.2011.1143

26. Sattar A A, El-Sayed H M, Agami W R and Ghani A A, American J Appl Sci., 2007, 4(2), 89-93; DOI:10.3844/ajassp.2007.89.93

27. Shinde N S, Khot S S, More R M, Kale B B, Basavaiah N, Watawe S C and Vaidya M M, Int J Chem Phy Sci., 2014, 3, 27-36.

28. Mahesh K A, Appa Rao P, Chaitanya V M, Choudary G S V R K and Rao K H, J Mod Phys., 2011, 2(9), 1083-1087; DOI:10.4236/jmp.2011.29132

29. Chaitanya M, Choudary G S V R K, Mahesh K A and Rao K H, Physics Research International., 2014, 579745; DOI:10.1155/2014/579745

30. Mazen S A and Elmosalami T A, J Cond Matter Phys., 2011, 820726; DOI:10.5402/2011/820726 